INOBIS: Jurnal Inovasi Bisnis dan Manajemen Indonesia

Volume 03, Nomor 04, September 2020

Veronika Agustini Srimulyani

\title{
Talent Management dan Konsekuensinya terhadap Employee Engagement dan Employee Retention
}

\author{
Veronika Agustini Srimulyani* \\ Universitas Katolik Widya Mandala Surabaya \\ sveronikaagustinis@gmail.com
}

\begin{abstract}
Abstrak
To gain a competitive advantage, employee engagement is indispensable. Therefore, an effective talent management system is needed in order to increase employee engagement. The aim of this research at knowing talent management at the XYZ Foundation in Madiun City and analyzing the impact of talent management on employee engagement and employee retention. This study also aims to analyze the effect of employee engagement as mediating the relationship of talent management with employee retention. The number of respondents in the study were 69 employees. Data gathered were initially analysed using SPSS version 22.0. From the descriptive analysis, it was found that: 1) employee response to talent management at XYZ Foundation as a whole was high; 2) work engagement on XYZ Foundation was high; 3) employee retention on XYZ Foundation was very high. The results of the hierarchical regression and path analysis indicated that: 1)talent management had a significant positive effect on work engagement; 2) talent management had a significant positive effect on employee retention; 3)work engagement had a significant positive effect on employee retention; 4) work engagement acts as a partial mediation of the influence of talent management on employee retention.
\end{abstract}

Keywords: talent management, employee retention.

\section{Pendahuluan}

Salah satu alat yang paling efektif dalam memastikan bahwa karyawan tetap terlibat dan berkomitmen pada pekerjaan mereka adalah talent management (Pandita \& Ray 2018), penting bagi organisasi modern karena munculnya ekonomi modern, generasi baru yang memasuki dunia kerja dan kebutuhan bisnis untuk menjadi lebih strategis dan kompetitif, yang menyiratkan cara-cara baru dalam mengelola sumber daya dan sumber daya manusia (Isfahani \& Boustani 2020). Rasa keterlibatan (engagement) atau komitmen terhadap pekerjaan karyawan ini memastikan pada gilirannya bahwa karyawan ini tetap bersama organisasi dalam jangka panjang. Talent management berhubungan dengan menarik, mengembangkan, dan mempertahankan bakat karyawan kunci organisasi (Mohammad 2015), bahkan talent management termasuk serangkaian proses lengkap untuk mengenali, mengelola orang untuk keberhasilan strategi bisnis yang digunakan organisasi. Talent management diyakini sebagai strategi penting untuk mempertahankan karyawan berbakat, tetapi studi akademik yang mengeksplorasi hubungan keduanya terbatas (Narayanan et al. 2018), berhubungan positif signifikan dengan employee engagement (Bolarinwa dan Lukman 2017). Alias et al. (2014) menemukan bahwa talent management practices yang terdiri dari managerial support, employee career development, dan rewards \& recognitions berdampak positif secara signifikan pada employee engagement dan employee retention. Kajian lain (Isfahani \& Boustani 2020) 


\section{Veronika Agustini Srimulyani}

menunjukkan bahwa ada dampak signifikan antara manajemen talent pada kepercayaan organisasi dan retensi karyawan dalam organisasi.

Agar organisasi mendapatkan keunggulan kompetitif di pasar, karyawan perlu terlibat di tempat kerja sehingga diperlukan sistem manajemen bakat yang efektif karena dapat meningkatkan employee engagement. Aspek persaingan dan kurangnya ketersediaan karyawan yang berbakat dan terampil yang dihadapi berbagai organisasi, maka menemukan dan mempertahankan karyawan berbakat dan memiliki keterlibatan yang tinggi menjadi prioritas utama untuk organisasi (Fegley 2006). Employee engagement adalah salah satu isu terkini yang berkembang dalam pengelolaan SDM. Dalam beberapa tahun terakhir konsep employee engagement mendapatkan perhatian karena kurangnya employee engagement merugikan keberhasilan bisnis (Gair 2018); merupakan kunci dalam mempertahankan talent/bakat (Glen, 2006). Engagement sendiri merupakan kekuatan yang mengikat antara organisasi dan pegawai baik secara emosional, rasional maupun motivasional yang mampu mendorong kinerja optimal individu sehingga membuat organisasi mampu mencapai tujuannya memiliki keunggulan bersaing. Zafar et al. (2014) menyatakan bahwa tingginya employee engagement terhadap organisasi akan meningkatkan retensi. Di lain pihak, pada era saat ini, organisasi banyak menghadapi tantangan dalam hal employee retention. Iles et al. (2010) mendefinisikan employee retention sebagai upaya sistematis oleh pengusaha untuk membangun suasana kerja yang kondusif yang mempromosikan budaya retensi; merupakan kemampuan organisasi untuk mempertahankan karyawan kunci yang dimiliki perusahaan untuk tetap loyal terhadap organisasi. Oleh karena itu organisasi termasuk organisasi perlu mengembangkan program employee retention yang tepat dan berkelanjutan, karena jika suatu organisasi tidak dapat mempertahankan karyawan yang dimiliki ditandai dengan meningkatnya employee turnover, maka hal ini merupakan suatu sinyal bahwa organisasi tersebut memiliki manajemen yang buruk dan perencanaan yang tidak matang dalam hal SDM, dalam hal ini merupakan bagian dari talent management.

Berdasarkan uraian sebelumnya, penelitian dilakukan dengan tujuan untuk mendapatkan gambaran secara empiris mengenai talent management dan konsekuensinya pada employee engagement dan employee retention baik pada tenaga pendidik maupun tenaga nonkependidikan pada Yayasan XYZ Madiun, agar pihak pengelola dapat mendapatkan informasi yang berguna bagi efektifitas pengelolaan SDM yang dimilikinya.

\section{Landasan Teori dan Pengembangan Hipotesis}

\section{Talent Management}

Kata talent atau talenta merupakan faktor pembeda kinerja setiap pegawai di dalam organisasi atau perusahaan. Jika organisasi ingin dan terus menumbuhkembangkan organisasinya, maka organisasi wajib menfokuskan kepada hal mencari, menarik dan mempertahankan para karyawan terbaik. Organisasi yang baik adalah organisasi yang visi, misi dan nilai organisasi yang telah ditetapkan, dijalankan oleh sejumlah karyawan yang bertalenta yang bekerja bersama-sama dan bersinergi (Pella dan Afifah 2011). Talent management pada awalnya dirancang untuk meningkatkan proses perekrutan dan pengembangan orang-orang dengan keterampilan dan bakat yang diperlukan untuk memenuhi kebutuhan organisasi saat ini. Berbagai aspek manajemen bakat adalah perekrutan, seleksi, on-boarding, pendampingan, manajemen kinerja, pengembangan karir, pengembangan kepemimpinan, perencanaan pengganti, perencanaan karier, pengakuan dan penghargaan (Heinen dan O'Neill 2004; Scheweyer 2004). Talent management didefinisikan sebagai proses sistematis dan dinamis 


\section{Veronika Agustini Srimulyani}

untuk menemukan, mengembangkan, dan mempertahankan bakat (Isfahani dan Boustani 2014).

Berdasarkan penelitian yang dilakukan oleh The Office of Talent Management and Organizational Development (2010), talent management terdiri dari 4 proses utama, 4 sub proses. Empat proses utama dari talent management adalah: 1) Inclusion adalah keadaan dimana individu merasa sebagai bagian proses organisasi; 2) Engagement adalah hubungan diantara organisasi dengan pegawai; proses engagement di dalam model talent management ini adalah memastikan pegawai antusias mengenai pekerjaan dan mengambil langkah positif untuk meningkatkan reputasi organisasi; 3) Competencies, memastikan pegawai memiliki kompetensi yang tepat untuk bekerja di dalam organisasi dan memenuhi tujuannya; 4) Retention, memastikan pegawai tetap bertahan di organisasi dan tidak pindah ke organisasi lain.

\section{Employee Engagement}

Employee engagement adalah salah satu isu terkini yang berkembang dalam pengelolaan sumber daya manusia, berperan dalam mempertahankan bakat di organisasi apa pun. Employee engagement dianggap sebagai faktor terpenting dalam keberhasilan organisasi mana pun dan organisasi berusaha keras untuk melibatkan karyawan dalam pekerjaan, dengan menawarkan mereka berbagai jenis imbalan berwujud dan tidak berwujud (Gulzar dan Durrani 2014). Employee engagement diartikan sebagai perasaan yang memotivasi dan mendedikasikan untuk menyelesaikan tugas secara efisien (Schaufeli et al. 2002); kesediaan karyawan dan kemampuannya untuk berkontribusi dalam konsekuensi perusahaan secara terus menerus (Towers Perrin 2003). Menurut Saks (2006), employee engagement dalam suatu organisasi adalah terdiri dari job engagement dan work engagement.

Rasa engagement terhadap organisasi dipengaruhi oleh beberapa faktor seperti faktor emosional dan rasional yang berkaitan dengan pekerjaan dan pengalaman kerja secara keseluruhan. Menurut Crim dan Seijts (2006) dengan employee engagement yang tinggi pegawai merasa antusias terhadap pekerjaan, peduli terhadap masa depan organisasi, dan memiliki suatu keinginan untuk memberikan kinerja yang terbaik agar organisasi sukses. Menurut Schaufeli et al. (2002) employee engagement adalah keadaan motivasional positif karyawan yang mengandung karakteristik vigor, dedication, dan absorption (Schaufeli et al. 2002). Vigor diartikan sebagai level energi dan resiliensi tinggi pegawai dan adanya kemauan untuk menginvestasikan tenaga, presistensi dan energik; dedication diartikan sebagai keterlibatan tinggi pegawai yang ditandai oleh antusiasme dan rasa bangga dan inspirasi; absorption diartikan sebagai keadaan keterlibatan tinggi pegawai atas pekerjaannya (sulitnya memisahkan pegawai dari pekerjaannya) (Saks 2006). Hal ini berarti pegawai yang engaged melakukan pekerjaan dengan semangat, penuh dedikasi, dan menikmati proses pemenuhan tanggung jawabnya. Employee engagement adalah suatu tingkatan dimana pegawai memiliki sikap positif dan kepercayaan terhadap organisasi beserta nilai-nilai yang ada didalamnya, sehingga pegawai berkomitmen secara emosional dan antusias pada pekerjaannya.

\section{Employee Retention}

Employee retention atau retensi pegawai merupakan kemampuan organisasi untuk mempertahankan pegawai potensial yang dimiliki perusahaan untuk tetap loyal terhadap organisasi. Menurut Mathis dan Jackson (2006: 126), retensi merupakan upaya untuk mempertahankan agar tetap berada dalam organisasi guna mencapai tujuan organisasi. Menurut Sumarni (2008), employee retention merupakan kemampuan perusahaan untuk 


\section{Veronika Agustini Srimulyani}

mempertahankan karyawan potensial yang dimiliki perusahaan untuk tetap loyal terhadap perusahaan. Employee retention sering diartikan sebagai upaya untuk mempertahankan karyawan di dalam organisasi, mengacu pada berbagai kebijakan dan praktik yang mengarahkan karyawan agar bertahan di organisasi untuk jangka waktu yang lebih lama. Setiap organisasi menginvestasikan waktu dan uang untuk mengembangkan rekrutmen baru agar karyawan siap bekerja dan dapat menyamai karyawan yang sudah ada. Oleh karena itu, kehilangan pegawai selalu berarti kehilangan pengetahuan, modal, keahlian, dan pengalaman. Bila organisasi kehilangan seseorang dengan banyak pengetahuan dan terlatih, pada dasarnya organisasi telah kehilangan pendapatan yang seharusnya dihasilkan karyawan tersebut.

\section{Pengembangan Hipotesis}

Pada era revolusi industri 4.0 saat ini employee retention menjadi tantangan setiap organisasi karena tingginya tingkat persaingan, terlepas dari ukuran, teknologi, dan fokus pasar yang dihadapi organisasi. Talent management adalah kegiatan penting yang memungkinkan organisasi untuk memiliki orang yang tepat dengan keterampilan dan keahlian untuk memenuhi kebutuhan sekarang dan masa depan perusahaan (Thiriku \& Were, 2016) karena memengaruhi secara positif employee engagement (Mohammed 2005; Narayanan et al. 2018); serta berhubungan secara positif dan signifikan dengan retensi karyawan (Sutanto dan Kurniawan, 2016; Coetzee dan Stoltz 2015; Karuri dan Nahashon 2015). Salah satu cara organisasi secara global dapat mempertahankan keunggulan kompetitif mereka adalah dengan mempertahankan orang-orang yang memiliki keterampilan, kompetensi, dan motivasi yang dibutuhkan. Chaturvedi dan Sangwan (2016) melakukan kajian dampak pemetaan kompetensi pada perekrutan, wawancara, seleksi, penempatan, manajemen kinerja dan penghargaan, pelatihan dan pengembangan, perencanaan karier dan suksesi yang memainkan peran utama dalam manajemen bakat dan retensi.

Penelitian lain (Zafar et al. 2014) menyatakan bahwa tingginya employee engagement terhadap organisasi dapat meningkatkan retensi, sedangkan Alias et al. (2014) menemukan bahwa talent management practices yang terdiri dari managerial support, employee career development, dan rewards \& recognitions berpengaruh langsung dan tidak langsung terhadap employee retention dengan employee engagement sebagai pemediasi. Isfahani dan Boustani (2014) menemukan bahwa talent management yang terdiri dari dimensi: succession planning, job experience, training, coaching, mentoring, and career management berpengaruh positif siginifikan terhadap employee retention baik secara langsung maupun tidak langsung dengan organizational trust sebagai pemediasi. berikut:

Berdasarkan uraian teori dan hasil penelitian terdahulu dirumuskan hipotesis sebagai

H1:Talent management berpengaruh positif signifikan terhadap employee engagement.

$\mathrm{H} 2$ :Talent management berpengaruh positif signifikan terhadap employee retention.

H3:Employee engagement berpengaruh positif signifikan terhadap employee retention.

$\mathrm{H} 4:$ Employee engagement memediasi pengaruh talent management terhadap employee retention. 
$\mathrm{H} 2$

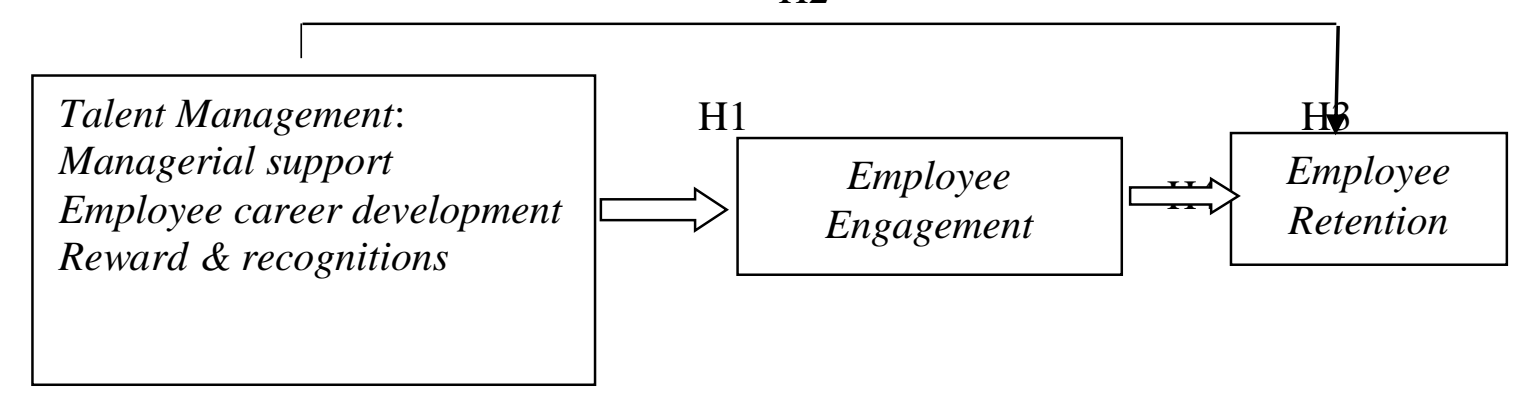

Gambar 1. Model Penelitian

Dari gambar 1 dapat dilihat bahwa employee engagement dapat dimungkinkan terbentuk oleh praktek talent management yang terdiri dari managerial support, employee career development, dan rewards \& recognitions dan selanjutnya employee engagement berdampak pada employee retention.

\section{Metode Penelitian}

Penelitian ini merupakan penelitian empiris dengan metode kuantitatif, dengan metode survei, yaitu penelitian yang mengambil sampel dari suatu populasi dan menggunakan kuesioner sebagai alat pengumpul data. Populasi penelitian ini adalah pegawai tetap dan pegawai tidak tetap baik tenaga pendidik, tenaga kependidikan dan tenaga penunjang pada Yayasan XXX Madiun yang berjumlah 69 orang.

Variabel yang digunakan dalam penelitian ini yaitu talent management (TM), employee engagement, dan employee retention. Pada tabel 1 berikut dapat dilihat definisi operasional dan pengukuran dari masing-masing variabel.

Tabel 1. Definisi Operasional dan Pengukuran Variabel

\begin{tabular}{|c|c|c|c|c|}
\hline Variabel & Definisi Operasional & Dimensi & $\begin{array}{l}\text { Jumlah } \\
\text { Indikator }\end{array}$ & Literatur \\
\hline $\begin{array}{l}\text { TM: } \\
\text { 1. Managerial } \\
\text { support }\end{array}$ & $\begin{array}{l}\text { sesuatu yang dinilai } \\
\text { oleh karyawan sebagai } \\
\text { pertemuan dari } \\
\text { kebutuhan emosi } \\
\text { sosial, kesiapan } \\
\text { manajerial untuk } \\
\text { menghargai } \\
\text { peningkatan kerja, dan } \\
\text { kecenderungan } \\
\text { organisasi } \\
\text { untuk menyediakan } \\
\text { bantuan saat } \\
\text { dibutuhkan } \\
\text { untuk mengerjakan } \\
\text { sebuah pekerjaan yang } \\
\text { efektif }\end{array}$ & $\begin{array}{l}\text {-Organization care } \\
\text {-Value employee } \\
\text { contribution } \\
\text {-Social emotional } \\
\text { needs } \\
\text { The organizational } \\
\text { will provide help }\end{array}$ & $\begin{array}{l}12 \text { item } \\
\text { Skala } \\
\text { Likert } \\
\text { dari } 1 \\
\text { sampai } 5 \\
\text { poin }\end{array}$ & $\begin{array}{l}\text { Rhoades \& } \\
\text { Eisenberger } \\
(2002) \\
\text { Aselage } \\
\& \\
\text { Eisenberger } \\
(2003)\end{array}$ \\
\hline
\end{tabular}




\section{Veronika Agustini Srimulyani}

\begin{tabular}{|c|c|c|c|c|}
\hline $\begin{array}{l}\text { 2.Employee } \\
\text { career } \\
\text { development }\end{array}$ & $\begin{array}{l}\text { kegiatan pengelolaan } \\
\text { SDM yang bertujuan } \\
\text { untuk memperbaiki } \\
\text { dan meningkatkan } \\
\text { efektifitas pelaksanaan } \\
\text { pekerjaan oleh para } \\
\text { pegawai agar semakin } \\
\text { mampu memberikan } \\
\text { kontribusi terbaik } \\
\text { dalam mewujudkan } \\
\text { tujuan organisasi }\end{array}$ & - & 11 item & $\begin{array}{l}\text { Nawawi } \\
(2001)\end{array}$ \\
\hline \begin{tabular}{|l|} 
3. Rewards \& \\
Recognitions
\end{tabular} & $\begin{array}{l}\text { Pengakuan dan } \\
\text { penghargaan } \\
\text { merupakan } \\
\text { wujud balas jasa } \\
\text { organisasi terhadap } \\
\text { keja } \\
\text { yang dilakukan } \\
\text { pegawai } \\
\end{array}$ & $\begin{array}{l}\text { Recognitions } \\
\text { (pengakuan) dari } \\
\text { pimpinan } \\
\text { Reward intrinsik } \\
\text { Reward ekstrinsik } \\
\text { langsung } \\
\text { Reward Ekstrinsik } \\
\text { tidak langsung }\end{array}$ & $\begin{array}{l}3 \text { item } \\
3 \text { item } \\
3 \text { item } \\
4 \text { item }\end{array}$ & $\begin{array}{l}\text { Robbins \& } \\
\text { Judge (2008) }\end{array}$ \\
\hline Variabel & Definisi Operasional & Dimensi & $\begin{array}{c}\text { Jumlah } \\
\text { Indikator }\end{array}$ & Literatur \\
\hline $\begin{array}{l}\text { Employee } \\
\text { Engagement }\end{array}$ & $\begin{array}{l}\text { Menggambarkan } \\
\text { sebagai sikap positif } \\
\text { seseorang (pegawai) } \\
\text { yang meliputi } \\
\text { komitmen, } \\
\text { keterlibatan dan } \\
\text { keterikatan terhadap } \\
\text { nilai-nilai budaya dan } \\
\text { pencapaian } \\
\text { keberhasilan } \\
\text { organisasi } \\
\end{array}$ & $\begin{array}{l}\text { Vigor } \\
\text { Dedication } \\
\text { Absorption }\end{array}$ & $\begin{array}{l}6 \text { item } \\
5 \text { item } \\
6 \text { item } \\
\text { Skala } \\
\text { Likert } \\
\text { dari } 1 \\
\text { sampai } 5 \\
\text { poin. }\end{array}$ & $\begin{array}{l}\text { Schaufeli et } \\
\text { al. (2002) }\end{array}$ \\
\hline $\begin{array}{l}\text { Employee } \\
\text { Retention }\end{array}$ & $\begin{array}{l}\text { Usaha } \\
\text { mempertahankan dan } \\
\text { atau meningkatkan } \\
\text { kondisi fisik, mental } \\
\text { dan sikap pegawai, } \\
\text { agar pegawai tetap } \\
\text { loyal dan bekerja } \\
\text { produktif untuk } \\
\text { menunjang } \\
\text { tercapainya tujuan } \\
\text { organisasi. }\end{array}$ & - & $\begin{array}{l}10 \text { item } \\
\text { Skala } \\
\text { Likert } \\
\text { dari 1 } \\
\text { sampai } 5 \\
\text { poin. }\end{array}$ & Rossi (2000) \\
\hline
\end{tabular}

Dalam menganalisis dan menginterpretasikan data, digunakan metode analisis deskriptif dan metode analisis verifikatif. Untuk menggambarkan karakteristik responden dan variabel penelitian digunakan analisis deskriptif dan pengujian hipotesis penelitian digunakan uji statistik yang relevan, yang diolah menggunakan software IBM SPSS Statistic (22 Version). 


\section{Veronika Agustini Srimulyani}

Pengujian data meliputi: 1) uji kualitas data (uji valiliditas dan uji reliabilitas); 2) analisis statistik deskriptif, dan analisis verifikatif yang meliputi: 3 ) uji asumsi klasik (uji normalitas data, uji multikoliniearitas, dan uji heteroskedastisitas, sedangkan uji autokorelasi tidak lakukan karena data yang dianalisis data cross section, bukan data times series), analisis regresi hirarkis (hierarchy regression analysis), dan analisis jalur (path analysis). Untuk uji goodness of fit dilihat dari nilai statistik $\mathrm{t}$.

\section{Pembahasan}

Gambaran tentang profil responden dan deskripsi variabel yang diukur disajikan pada tabel 2 dan tabel 3 berikut.

Tabel 2. Profil Responden

\begin{tabular}{|l|r|r|}
\hline \multicolumn{1}{|c|}{ Keterangan } & Jumlah (Orang) & Presentase (\%) \\
\hline Jenis Kelamin & 24 & $34,78 \%$ \\
\hline Laki-laki & 43 & $62,31 \%$ \\
\hline Perempuan & 2 & $2,91 \%$ \\
\hline Tidak Mengisi & 69 & $100 \%$ \\
\hline Jumlah & & \\
\hline Tingkat Pendidikan & 2 & $2,9 \%$ \\
\hline SD & 5 & $7,45 \%$ \\
\hline SMP & 20 & $28,99 \%$ \\
\hline SMK & 2 & $2,9 \%$ \\
\hline Diploma 3 & 36 & $52,17 \%$ \\
\hline Strata 1 S1) & 1 & $1,45 \%$ \\
\hline Strata 2 (S2) & 3 & $4,34 \%$ \\
\hline Tidak Mengisi & 69 & $100 \%$ \\
\hline Jumlah & & \\
\hline Masa Kerja & 7 & $10,15 \%$ \\
\hline$\leq 1$ tahun & 10 & $14,49 \%$ \\
\hline$>1-5$ tahun & 14 & $20,29 \%$ \\
\hline$>5-10$ tahun & 15 & $21,74 \%$ \\
\hline$>10-15$ tahun & 6 & $8,7 \%$ \\
\hline$>15-20$ tahun & 4 & $5,79 \%$ \\
\hline$>20-25$ tahun & 4 & $5,79 \%$ \\
\hline$>25-30$ tahun & 6 & $8,7 \%$ \\
\hline$>30$ tahun & 3 & $4,35 \%$ \\
\hline Tidak Mengisi & 69 & $100 \%$ \\
\hline Jumlah & & \\
\hline Sumber: Data prmat & & \\
\hline
\end{tabular}

(Sumber: Data primer, diolah)

Jika dilihat dari jenis kelamin sebanyak $34,78 \%$ responden berjenis kelamin laki-laki dan $62,31 \%$ berjenis kelamin perempuan. Jika dilihat dari tingkat pendidikan sebagian besar responden $(52,17 \%)$ memiliki tingkat pendidikan S1; SMA/SMK sebanyak 28,99\%; SMP sebanyak 7,45\%; SD sebanyak 2,9\%; D3 sebanyak 2,9\%, dan tingkat pendidikan strata 2 (S2) sebanyak $1,45 \%$, serta tidak mengisi sebanyak 4,34\%. Jika dilihat dari masa kerja, sebanyak 21,74\% memiliki masa kerja >10-15 tahun; sebanyak 20,29\% memiliki masa kerja $>5-10$ tahun; sebanyak 14,49\% memiliki masa kerja >1-5 tahun; sebanyak 10,15\% memiliki masa kerja $\leq 1$ tahun; sebanyak 8,7\% memiliki masa kerja $>15-20$ tahun, sebanyak 8,7\% memiliki 


\section{Veronika Agustini Srimulyani}

masa kerja > 30 tahun, sebanyak 5,79\% memiliki masa kerja>20-25 tahun; sebanyak 5,79\% memiliki masa kerja>25-30 tahun, dan sebanyak 4,35\% tidak mengisi.

Nilai rata-rata total atas variabel-variabel yang diteliti berdasarkan tanggapan pegawai Yayasan XYZ atas kuesioner yang diisi, dapat dilihat pada tabel 3 berikut.

Tabel 3. Nilai Rata-Rata Variabel Penelitian

\begin{tabular}{|l|c|c|}
\hline \multicolumn{1}{|c|}{ Variabel } & Mean & Kriteria \\
\hline Management Support (MS) & 4,1389 & Tinggi \\
Employee Career Development (ECD) & 2,6917 & Cukup/Sedang \\
Rewards \& Recognitions (RR) & 4,0513 & Tinggi \\
\hline Talent Management (TM) & 3,6273 & Tinggi \\
\hline Employee Engagement (EE) & 3,6914 & Tinggi \\
\hline Employee Retention (ER) & 4,2145 & Sangat Tinggi \\
\hline
\end{tabular}

Tanggapan karyawan atas talent management yang diukur dengan 3 kebijakan HRM yang dikembangkan Yayasan XYZ Madiun sebagai berikut: untuk managerial support dan rewards \& recognitions dinilai tinggi oleh pegawai; sedangkan untuk employee career development dinilai cukup tinggi oleh pegawai. Namun jika dilihat dari nilai rata-rata talent management secara keseluruhan adalah tinggi. Employee engagement adalah keterlibatan penuh dalam pekerjaan dan sangat antusias terhadap pekerjaan yang ditangani dan dari tabel 3 dapat dilihat bahwa tingkat employee engagement adalah tinggi, dan dengan tingginya employee engagement diprediksikan produktivitas dan retensi pegawai dapat semakin meningkat, sehingga diharapkan dapat meningkatkan pula kepuasan siswa dan orang tua atas layanan pendidikan yang disediakan Yayasan. Dari tabel 3 dapat dilihat bahwa employee retention sangat tinggi, hal ini berarti praktek dan kebijakan yang dirancang Yayasan dalam menciptakan lingkungan kerja kondusif dapat mengikat karyawan untuk tetap bersama organisasi, sehingga mengurangi perputaran pegawai sudah efektif, karena pegawai memiliki tingkat retensi yang cenderung sangat tinggi, dan ini berarti intention to quit dan turnover pegawai rendah.

Untuk pengujian pengaruh secara parsial, alat uji yang digunakan adalah uji t dan untuk hipotesis mediasional atau mediational hypothesis, diuji dengan causal step berdasarkan ketentuan dari Baron dan Kenny (1986).

\section{Uji Pengaruh Secara Parsial (Uji t)}

Uji t adalah alat uji untuk mengetahui dan mengukur variabel-variabel yang mempunyai keeratan pengaruh terhadap variabel terikat (Y) secara parsial. Pengujian uji t dilakukan dengan melihat apakah nilai-nilai koefisien yang diperoleh berbeda secara signifikan atau tidak antara $t$ hitung dan $t$ tabel atau $p$ value (sig) dengan tingkat keyakinan $5 \%(\alpha=0,05)$. Untuk t tabel dicari dengan tabel $\mathrm{t}$ dengan $\mathrm{df}=\mathrm{n}-\mathrm{k}$, dimana $\mathrm{k}$ merupakan jumlah variabel independen (Nugroho 2005: 54). Nilai-nilai koefisien regresi dan t-hitungnya (CR) diestimasi dari hasil analisis regresi, dapat dilihat pada tabel 4. 
Tabel 4. Ringkasan Hasil Analisis Regresi Untuk Pengujian t (Pengaruh Parsial)

\begin{tabular}{|c|c|c|c|c|c|c|c|c|}
\hline & & Estimate & S.E. & $\begin{array}{c}\text { Standardized } \\
\text { Coefficients } \\
\text { Beta }\end{array}$ & $\begin{array}{l}\text { C.R. } \\
\text { (t-hit) }\end{array}$ & t tabel & $\mathrm{P}$ & Keterangan \\
\hline & \multicolumn{8}{|c|}{$\mathrm{EE}=\mathrm{a}_{0}+\mathrm{b}_{1} \mathrm{TM}+\mathrm{e}_{\mathrm{i}}=1,374+0,639 \mathrm{TM}$} \\
\hline $\mathrm{TM}$ & $\rightarrow \quad \mathrm{EE}$ & 0,639 & 0,215 & 0,341 & 2,972 & 1,667 & 0,004 & $\begin{array}{c}\text { Signifikan } \\
\text { H1 } \\
\text { diterima } \\
\end{array}$ \\
\hline & \multicolumn{8}{|c|}{ 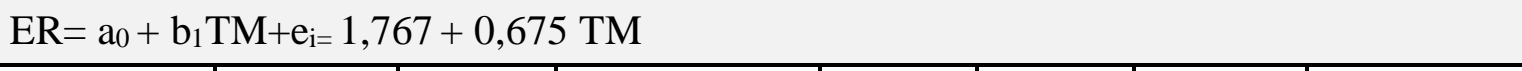 } \\
\hline $\mathrm{TM}$ & $\rightarrow \quad \mathrm{ER}$ & 0,675 & 0,164 & 0,448 & 4,106 & 1,667 & 0,000 & $\begin{array}{c}\text { Signifikan } \\
\text { H2 } \\
\text { diterima } \\
\end{array}$ \\
\hline & \multicolumn{8}{|c|}{$\mathrm{ER}=\mathrm{a}_{0}+\mathrm{b}_{1} \mathrm{EE}+\mathrm{e}_{\mathrm{i}=} 2,945+0,344 \mathrm{EE}$} \\
\hline $\mathrm{EE}$ & $\rightarrow \quad \mathrm{ER}$ & 0,344 & 0,089 & 0,428 & 3,872 & 1,667 & 0,000 & $\begin{array}{c}\text { Signifikan } \\
\text { H3 } \\
\text { diterima } \\
\end{array}$ \\
\hline
\end{tabular}

(Sumber: Output SPSS)

$\mathrm{H} 2(\mathrm{~b}=0,428 *)$

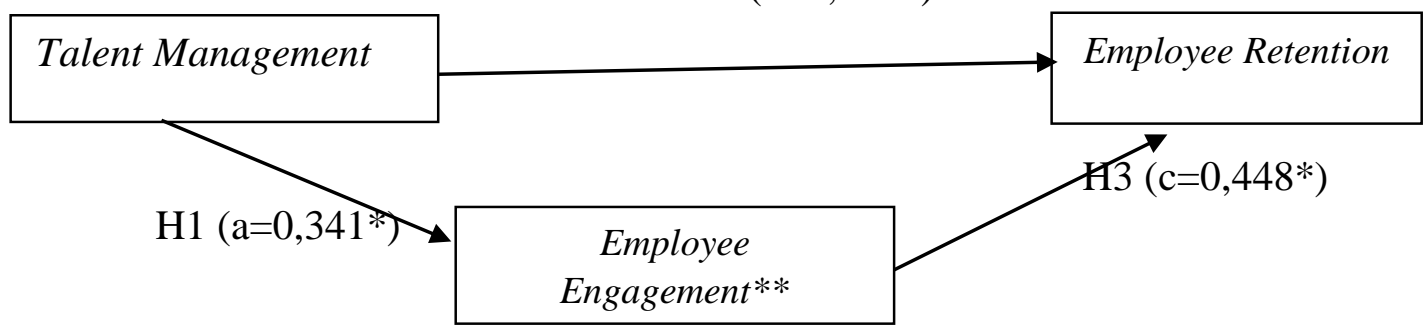

*Sig pada $\alpha=0.05 \quad * *$ Partial Mediation

Gambar 2. Model Penelitian Akhir (Signifikan)

\section{Pengaruh Talent Management terhadap Employee Engagement}

Pegawai tidak hanya memegang peran sebagai resource dalam organisasi, namun telah bertransformasi sebagai human capital, orang yang ada dibelakang semua proses operasional organisasi. Untuk mempertahankan human capital yang dimiliki, diperlukan suatu engagement pegawai melalui praktek manajemen sumber daya manusia, diantaranya talent management dan employee engagement. Hasil pengujian (tabel 4) diperoleh nilai koefisien pengaruh talent management terhadap employee engagement sebesar 0,639 atau 63,90\% dengan nilai standardized coefficients beta sebesar 0,341 dan nilai t hitung sebesar 2,972>1,667 serta nilai signifikansi sebesar $0,000<0,05$; hal ini berarti (H1) yang menyatakan bahwa talent management berpengaruh positif signifikan terhadap employee engagement, diterima. Hasil penelitian mendukung penelitian Alias et al. (2014); Mohammed (2015); Bolarinwa dan Lukman (2017), dan Narayanan et al. (2018) yang menemukan pengaruh positif signifikan talent management terhadap employee engagement. 


\section{Veronika Agustini Srimulyani}

Berdasarkan nilai rata-rata respon pegawai atas talent management yang diukur dengan 3 kebijakan pengelolaan sumber daya manusia yang dikembangkan Yayasan XYZ Madiun diperoleh hasil bahwa: managerial support dan rewards \& recognitions dinilai tinggi oleh pegawai dan untuk employee career development dinilai cukup tinggi oleh pegawai. Aspek pengembangan karir pada pegawai Yayasan tersebut merupakan salah satu faktor penting yang dapat menyebabkan keterikatan pegawai pada Yayasan semakin tinggi. Ketika pegawai memiliki kesempatan pengambangan diri berarti pegawai mempunyai kesempatan untuk mengembangkan kemampuan, mempelajari keahlian baru, mendapatkan pengalaman baru dan menyadari potensinya. Pengembangan diri yang didukung rancangan karir yang sesuai pada pegawai, hal ini berarti organisasi menjadikan pegawai sebagai bentuk investasi bagi pengembangan organisasi. Oleh karena itu perbaikan kebijakan dan hal-hal yang berhubungan dengan pengembangan karir pegawai menjadi tanggung jawab bersama antara pegawai dan manajemen Yayasan, agar pelaksanaannya berkontributif positif bagi kemajuan diri pegawai maupun kemajuan organisasi.

Jadi untuk menumbuhkan keterikatan pegawai pada pekerjaan dan organisasi tempat kerja, diperlukan praktek talent management yang meliputi managerial support, employee career development, dan rewards \& recognitions. Hal ini mengindikasikan employee engagement dapat tumbuh dan berkembang karena: pertama; kesiapan manajerial untuk menghargai peningkatan kerja dan penyediaan bantuan bagi pegawai saat dibutuhkan agar pegawai dapat meningkatkan efektifitas pelaksanaan pekerjaan; kedua; kemampuan organisasi harus meninjau rencana karir pegawai dan mengatur ulang rencana-rencana sesuai dengan kondisi yang berlaku, sehingga pegawai yang cerdas dan berbakat dapat memberikan kelebihan serta manfaat dalam jangka panjang sehingga semakin mampu memberikan kontribusi terbaik dalam mewujudkan tujuan organisasi; ketiga; adanya penghargaan dan pengakuan dari organisasi secara layak dan adil sebagai wujud balas jasa organisasi terhadap kerja yang dilakukan pegawai.

\section{Pengaruh Talent Management terhadap Employee Retention}

Hasil analisis pengaruh talent management terhadap employee retention (tabel 4) menunjukkan bahwa nilai koefisien regresi sebesar 0,675 atau $67,50 \%$ dengan nilai standardized coefficients beta sebesar 0,448 dan nilai t hitung sebesar 4,106>1,667 serta nilai signifikansi sebesar $0,000<0,05$; hal ini berarti $(\mathrm{H} 2)$ yang menyatakan bahwa talent management berpengaruh positif signifikan terhadap employee retention, diterima. Temuan ini sejalan dengan Alias et al. (2014); Isfahani dan Boustani (2014); Karuri dan Nahashon (2015); Chaturvedi dan Sangwan (2016) yang menunjukkan peran penting talent management pada peningkatan employee retention. Employee retention pada pegawai Yayasan sangat tinggi, hal ini berarti praktek dan kebijakan SDM yang dirancang Yayasan dapat menciptakan lingkungan kerja yang membuat pegawai ingin tetap bersama organisasi, dan ini berarti turnover intention to quit pegawai Yayasan dalam tingkat yang sangat rendah. Oleh karena itu pengelolaan human capital yang efektif oleh organisasi pada umumnya dapat berdampak pada pengurangan jumlah pegawai meninggalkan organisasi bahkan dapat menarik orang-orang berbakat dan berkualitas untuk bergabung dengan organisasi tersebut.

Semakin tinggi tingkat persaingan organisasi pendidikan di Indonesia mengakibatkan organisasi pendidikan dihadapkan pada tantangan untuk dapat bertahan hidup. Salah satu caranya adalah dengan meningkatkan kualitas tenaga pendidik dan non-pendidik yang dimilikinya. Pegawai yang memiliki keahlian, tenaga, dan kreativitas, atau yang biasa dikenal sebagai talenta, akan dibutuhkan oleh organisasi dan perlu dipertahankan oleh organisasi, untuk mencapai tujuannya. Hasil penelitian menunjukkan bahwa pengaruh talent management terhadap employee retention adalah positif dan signifikan. Hal ini didukung oleh tanggapan 


\section{Veronika Agustini Srimulyani}

pegawai atas management talent practices secara umum positif, serta adanya respon sangat tinggi/sangat baik karyawan khususnya pada item pernyataan tentang keberlanjutan bekerja dan tingkat stay in pegawai di Yayasan XYZ Madiun. Hasil ini mendukung Handoko (2008) yang menjelaskan bahwa salah satu keuntungan yang dihubungkan dengan level keterikatan pegawai yang tinggi adalah turnover pegawai yang rendah atau retensi pegawai yang tinggi. Hal ini mengindikasikan, semakin efektif praktek manajemen talenta maka semakin tinggi retensi pegawai.

\section{Pengaruh Employee Engagement Terhadap Employee Retention}

Pegawai yang engaged sangat berenergi, bersikap positif, dan berinisiatif pada pekerjaan sehingga menghasilkan efek positif bagi diri sendiri dan bagi organisasi. Hasil analisis pengaruh employee retention terhadap employee retention (tabel 4) menunjukkan bahwa nilai standardized coefficients beta sebesar 0,428 dengan nilai koefisien regresi sebesar 0,344 atau 34,40\% dan nilai t hitung sebesar 3,872>1,667 dengan nilai signifikansi sebesar $0,000<0,05$; hal ini berarti (H3) yang menyatakan bahwa employee engagement berpengaruh positif signifikan terhadap employee retention, diterima. Hasil ini sejalan dengan Zafar et al. (2014); Alias et al. (2014) yang menunjukkan bahwa employee engagement yang tinggi diyakini dapat meningkatkan talent retention.

Saat ini, employee engagement menjadi salah satu strategi utama organisasi pada umumnya untuk mempertahankan human capital. Hewitt (2013:4) menyatakan bahwa employee engagement akan menghasilkan 3 elemen (3S) yaitu Say (berbicara positif tentang organisasi), Stay (bertahan dalam organisasi), dan Strive (termotivasi untuk bekerja lebih serius). Hasil penelitian menemukan bahwa employee engagement berpengaruh positif signifikan terhadap employee retention.Tingkat employee engagement Yayasan XYZ Madiun tinggi (tabel 3), hal ini berarti partisipasi aktif para pegawai dalam pekerjaan dapat memunculkan komitmen, keinginan berkontribusi dan rasa memiliki pegawai terhadap pekerjaan dan organisasi, termasuk timbulnya rasa saling percaya, semangat kerjasama, rasa bangga terhadap organisasi, dan loyalitas tinggi terhadap pekerjaan dan organisasi. Employee engagement dapat berdampak positif terhadap retensi pegawai, artinya employee engagement yang tinggi mampu mengurangi keinginan pegawai untuk berpindah (turnover intention) dan secara langsung mengurangi tingkat turnover.

\section{Pengaruh Talent Management terhadap Employee Retention melalui Employee Engagement sebagai Pemediasi}

Tabel 5. Ringkasan Hasil Analisis Regresi Untuk Pengujian Variabel Mediating

\begin{tabular}{|c|c|c|c|c|c|c|c|c|c|}
\hline & & & Estimate & S.E. & $\begin{array}{c}\text { Standardized } \\
\text { Coefficients } \\
\text { Beta }\end{array}$ & $\begin{array}{l}\text { C.R. } \\
\text { (t-hit) }\end{array}$ & $\mathrm{t}$ tabel & $\mathrm{P}$ & Keterangan \\
\hline \multicolumn{10}{|c|}{$\mathrm{EE}=1,374+0,639 \mathrm{TM}($ Pengaruh $\mathrm{X} \rightarrow \mathrm{M}($ Jalur a $)$} \\
\hline$\overline{\mathrm{TM}}$ & $\rightarrow$ & $\mathrm{EE}$ & 0,639 & 0,215 & 0,341 & 2,972 & 1,667 & 0,004 & Signifikan \\
\hline \multicolumn{10}{|c|}{$\mathrm{ER}=1,767+0,675 \mathrm{TM}($ Pengaruh $\mathrm{X} \rightarrow \mathrm{Y}($ Jalur $\mathrm{c})$} \\
\hline TM & $\rightarrow$ & ER & 0,675 & 0,164 & 0,448 & 4,106 & 1,667 & 0,000 & Signifikan \\
\hline \multicolumn{10}{|c|}{$\mathrm{ER}=1,423+0,515 \mathrm{TM}+0,250 \mathrm{EE}($ Pengaruh $\mathrm{X}, \mathrm{M} \rightarrow \mathrm{Y})($ Jalur c' dan $\mathrm{b})$} \\
\hline TM & $\rightarrow$ & ER & 0,515 & 0,166 & 0,342 & 3,094 & 1,667 & 0,003 & Signifikan \\
\hline $\mathrm{EE}$ & $\rightarrow$ & ER & 0,250 & 0,089 & 0,311 & 2,809 & 1,667 & 0,007 & Signifikan \\
\hline
\end{tabular}

(Sumber: Output SPSS) 


\section{Veronika Agustini Srimulyani}

Berdasarkan hasil estimasi ketiga model regresi pada tabel 5, semua persyaratan untuk tercapainya mediasi terpenuhi (Baron and Kenny 1986): Pertama, variabel independen (talent management) berpengaruh signifikan terhadap variabel mediator (employee engagement), dengan koefisien regresi ( $\boldsymbol{a}$ ) sebesar 0,341; Kedua, variabel independen (talent management) berpengaruh signifikan terhadap variabel dependen (employee retention) dengan koefisien regresi (c) sebesar 0,448; dan Ketiga, variabel mediator (employee engagement) berpengaruh signifikan terhadap variabel dependen (employee retention) dengan koefisien regresi $(\boldsymbol{b})$ sebesar 0,331. Peran employee engagement sebagai pemediasi terjadi karena pengaruh variabel independen (talent management practices) terhadap variabel dependen (employee retention) lebih rendah pada persamaan ketiga $\left(c^{\prime}=0,342\right)$ dibandingkan pada persamaan kedua $(\mathrm{c}=0,448)$, namun karena pengaruhnya tetap signifikan maka dinyatakan terjadi partial mediation. Hal ini berarti hipotesis 4 yang menyatakan: employee engagement memediasi pengaruh talent management terhadap employee retention, diterima.

Wacana employee engagement biasanya selalu dikaitkan dengan talent management yang sebagian organisasi masih menganggap itu sebagai program yang "high cost", meskipun hasilnya akan sangat bermanfaat dalam jangka panjang. Manajemen talenta adalah susunan proses sumber daya manusia organisasional yang dirancang untuk menarik, mengembangkan, memotivasi, dan mempertahankan pekerja yang produktif dan terikat (engaged), yang pada akhirnya dapat bertahan dalam jangka yang lama di organisasi. Jika tingkat employee engagement tinggi maka secara umum organisasi akan diuntungkan dengan berbagai hal seperti: 1) Dapat mempertahankan dan meningkatkan produktivitas pegawai karena pegawai merasa happy berkarya di organisasi tersebut, 2)Membantu mempertahankan pegawai terbaik, karena pegawai tidak mudah tergiur dengan tawaran organisasi lain, 3)Membantu pencapaian target perusahaan/organisasi, karena beberapa studi yang mengkorelasikan antara tingginya employee engagement dengan pencapaian target organisasi.

Hasil penelitian (tabel 5) menunjukkan bahwa employee engagement memediasi pengaruh talent management terhadap employee retention, dimana employee engagement sebagai partial mediation. Hasil ini mendukung Alias et al. (2014) menemukan bahwa talent management berpengaruh langsung dan tidak langsung terhadap employee retention dengan employee engagement sebagai pemediasi. Bentuk partial mediation ini menunjukkan bahwa employee engagement bukan satu-satunya pemediasi hubungan talent management terhadap employee retention, namun terdapat faktor pemediasi lain (Baron dan Kenny 1986). Faktor pemediasi lain misalnya organizational commitment (Anis et al. 2011); organizational citizenship behavior (Dash dan Pradhan 2014); organizational trust (Isfahani dan Boustani 2014).

\section{Kesimpulan}

Dari hasil analisis deskriptif, diketahui bahwa tanggapan pegawai atas talent management (managerial support, employee career development, dan rewards \& recognitions) dan employee engagement adalah tinggi, dan employee retention sangat tinggi. Dari hasil pengujian hipotesis ditunjukkan bahwa dampak talent management terhadap employee engagement dan employee retention adalah positif dan signifikan; dampak employee engagement terhadap employee retention adalah positif dan signifikan, employee engagement berperan sebagai pengaruh talent management terhadap employee retention adalah partial mediation, hal ini berarti bahwa praktek manajemen talenta yang efektif di organisasi dapat berdampak pada retensi pegawai melalui keterikatan pegawai, namun juga dapat berdampak langsung pada retensi pegawai. Hasil ini juga menunjukkan bahwa employee engagement bukan satu-satunya pemediasi hubungan talent management dengan employee retention, 
misalnya perilaku extra-role pegawai dan komitmen pegawai pada organisasi. Hasil pengujian pengaruh secara simultan juga menunjukkan bahwa talent management dan employee engagement berpengaruh positif dan signifikan terhadap employee retention.

\section{Daftar Pustaka}

Alias, N.E., Norzanah, M.N. \& Hassan, R. (2014) "Examining the Mediating Effect of Employee Engagement on the Relationship between Talent Management Practices and Employee Retention in the Information and Technology (IT) Organizations in Malaysia." Journal of Human Resources Management and Labor Studies, 2 (2): 227242.

Anis, Atif, Kashif-ur-Rehman, Ijaz-ur-Rehman, Khan, M.A. \& Humayoun, A.A. (2011) "Impact of Organizational Commitment on Job Satisfaction and Employee Retention in Pharmaceutical." African Journal of Business Management, 5(17),7316-7324.

Aselage, J. \& Eisenberger, R. (2003) "Perceived Organizational Support and Psychological Contracts: A Theoretical Integration.” Journal of Organizational Behavior, 24(5):491

Baron, R. M \& Kenny, D. A. (1986) "The Moderator-Mediator Variable Distinction in Social Psychological Research: Conceptual, Strategic, and Statistical Considerations." Journal of Personality and Social Psychology, 51(6),1173-1182.

Bolarinwa, I. \& Lukman, A. (2017) "Talent Management and Employee Engagement: a Study of Guaranty Trust Bank in Ilorin Metropolis Kadiri."Governance and Management Review, 2(2), 37-46.

Chouhan, V. S. \& Srivastava, S. (2013) "Competency mapping for HR professionals in IT industry." The International Journal of Management, 2(3), 1-6.

Chaturvedi, A. and Sangwan, K. (2016) "Impact of Job Satisfaction on Retention of Employees in BPO Industry." International Multidisciplinary Journal, 5 Issue 11, 1-6.

Coetzee, M. \& Stoltz, E. (2015) 'Employees' Satisfaction with Retention Factors: Exploring the Role of Career Adaptability." Journal of Vocational Behavior, 89, 83-91.

Crim, D. \& Gerard Seijts, G. (2006) "What Engages Employees the Most OR, the Ten Cs of Employee Engagement." Business Journal, Issues March/April 2006, diakses dari https://iveybusinessjournal.com/publication/, pada tanggal 14 Januari 2020.

Dash, S. \& Pradhan, R.K. (2014) "Determinants \& Consequences of Organizational Citizenship Behavior: A Theoretical Framework for Indian Manufacturing Organizations." International Journal of Business and Management Invention, 3(1): $17-27$.

Fegley, S. (2006) “Talent Management Survey Report.” SHRM Research, Alexandria, VA.

Gair, S. (2018) "The impact of talent management on employee engagement in a South African car sales company." Mini-dissertation Submitted in Partial Fulfilment of The Requirements for The Degree Master of Business Administration at the North-West University, diunduh dari https://repository.nwu.ac.za/bitstream/handle/10394/30975/, pada tanggal 20 November 2020.

Glen, C. (2006) "Key skills Retention and Motivation: the War for Talent Still Rages and Retention is the High Ground." Industrial and Commercial Training, 38(1), 37-45

Gulzar, S.S. \& Abida Durrani, A. (2014) "Impact of Succession Planning on Employee Engagement in Telecommunication Sector in Rawalpindi, Pakistan." European Journal of Business and Management, 6 (37), 274-281.

Handoko, H.T. (2008) Membangun Employee Engagement (Keterikatan Karyawan), diunduh dari http://www.mediakalla.com/, pada tanggal 10 November 2020. 
Heinen, S.J. \& O'Neill, C. (2004) "Managing talent to maximize performance", Employment Relations To day, 31, p. 2.

Iles, P., X. Chuai \& D. Preece (2010) "Talent management and HRM in multinational companies in Beijing: Definitions, Differences and Drivers." Journal of World Business, 45(2), 179-189.

Isfahani, A.C. \& Boustani, H. (2020) "Effects of Talent Management on Employees Retention: The Mediate Effect of Organizational Trust" International Journal of Academic Research in Economics and Management Sciences, 3(5), 114-128.

Karuri, M. \& Nahashon, L. (2015) "Effect of Talent Management on Employee Outcomes: A Case Study of Central Bank of Kenya". Journal of Business and Change Management, Vol. 2 (43), 882-899.

Mathis, Robert L., \& Jackson, J.H. (2006) Human Resource Management. Salemba Empat: Jakarta.

Mohammed, A.Q. (2015) "The Impact of Talent Management on Employee Engagement, Retention and Value Addition in achieving Organizational Performance". International Journal of Core Engineering \& Management (IJCEM), 1, Issue 12, 142-152.

Narayanan, A., Rajithakumar, S., \& Menon, M. (2019) "Talent Management and Employee Retention: An Integrative Research Framework." Human Resource Development Review, 18 issue 2, 228-247.

Nawawi, H.(2001) Manajemen Sumber Daya Manusia untuk Bisnis yang Kompetitif, Cetakan Keempat. Yogyakarta: Penerbit Gadjah Mada University Press.

Nugroho, B.A. (2005). Strategi Jitu Memilih Metode Statistik. Penelitian dengan SPSS. Yogyakarta: Penerbit Andi.

Office of Talent \& Organizational Development Homepage. (2010) Diakses dari Office of Talent \& Organizational Development (houstontx.gov) pada tanggal 4 Januari 2020.

Pandita, D. \& Ray, S. (2018) "Talent Management and Employee Engagement-a MetaAnalysis of Their Impact on Talent Retention", Industrial and Commercial Training, $50(4), 185-199$.

Pella, D.A. \& Inayati, A. (2011) Talent Management Mengembangkan SDM untuk Mencapai Pertumbuhan dan Kinerja Prima, Jakarta: PT Gramedia.

Rhoades, L. \& Eisenberger, R.( 2002) "Perceived Organizational Support: A review of the Literature." Journal of Applied Psychology, 87 (4), 698-714.

Robbins, S. \& Timoty A. Judge, T.A. (2008) Perilaku Organisasi, Edisi 12, Jakarta: Salemba Empat.

Rossi, John F. (2000) Employee Retention: Why Do Employee Stay with A Company Research Seminar in Organization Management. St. Joseph's College. Patchogue NewYork, diunduh dari http://users.isp.com/jfrossi/subs/ersr.pdf pada tanggal 11 Januari 2020.

Saks, Alan M. (2006) "Antecedents and Consequences of Employee Engagement." Journal of Managerial Psychology, 21 Issue 7, 600-619.

Schaufeli, W. B., Salanova, M., Gonzalez-Roma, V., \& Bakker, A. B. (2002) "The Measurement of Engagement and Burnout: a Two Sample Confirmatory Factor Analytic Approach. Journal of Happiness Studies, 3, 71-92.

Scheweyer, A. (2004) Talent Management Systems: Best Practices in Technology Solutions for Recruitment, Retention and Workforce Planning. New York: Wiley.

Sumarni, M. (2008) "Pengaruh Employee Retention terhadap Turnover Intention dan Kinerja Karyawan.” Jurnal Akuntansi \& Manajemen Akmenika, 8 (1), 1-10.

Sutanto, E. M. \& Kurniawan, M. (2016) "The Impact of Recruitment, Employee Retention and Labor Relations to Employee Performance on Batik Industry in Solo City, Indonesia." International Journal of Business and Society, 17(2), 375-390. 
Thiriku, M. \& Were, S. (2016) "Effect of Talent Management Strategies on Employee Retention among Private Firms in Kenya: a Case of Data Centre LTD-Kenya." International Academic Journal of Human Resource and Business Administration, 2, Issue 2, 145-157.

Towers Perrin. (2003) Working Today: Understanding What Drives Employee Engagement. diunduh dari http://www.keepem.com/doc_files/Towers_Perrin_Talent_2003 (TheFinal).pdf pada tanggal 4 Januari 2020.

Zafar, F., Nawaz, A., Farooqui, A., Abdullah, M. \& Yousaf, I. (2014) 'Employees' Retention through Corporate Social Responsibility in Large Scale Organizations.” International Journal of Business and Behavioral Sciences, 4(1), 1-30. 